\title{
Transcriptional activity of an ovarian-specific promoter from rat in dairy goat granulosa cells
}

\author{
H.-Y. Liu*, M.-M. Yang*, Y.-H. Cui*, T. Ma*, X.-Q. Liu, L. Bai, \\ W.-P. Xiao, H.-B. Zhao, J.-Y. Peng, X.-B. Hu and B.-Y. Cao \\ Department of Animal Science and Technology, \\ Northwest A\&F University, Yangling, China \\ *These authors contributed equally to this study. \\ Corresponding author: B.-Y. Cao \\ E-mail: caobinyun@yahoo.com.cn
}

Genet. Mol. Res. 12 (1): 127-135 (2013)

Received May 29, 2012

Accepted October 10, 2012

Published January 24, 2013

DOI http://dx.doi.org/10.4238/2013.January.24.4

\begin{abstract}
Ovarian-specific promoter 1 (OSP-1) is a retrovirus-like element isolated from the complementary DNA library of rat that has been thought to be specifically expressed in ovary. To exploit this promoter in dairy goat ovary granulosa cells (GCs), OSP-1 from rat was used to construct the reporter vector pOSP-1-EGFP, in which egfp coding for enhanced green fluorescent protein (EGFP) was used as a reporter to examine the activity of OSP-1 in GCs. EGFP was successfully expressed in dairy goat GCs transfected with pOSP-1-EGFP. Reverse transcriptasepolymerase chain reaction analysis confirmed the tissue-specific transcription of EGFP messenger RNA in dairy goat GCs transfected with pOSP-1-EGFP. We concluded that OSP-1 promoter from rat can specifically drive foreign gene expression in dairy goat GCs. Thus, we obtained a tissue-specific regulation element and provided a potential tool for the research of regulation and development of the ovary in dairy goats.
\end{abstract}

Key words: OSP-1; Enhanced green fluorescent protein; Dairy goat granulosa cells; Reverse transcription-polymerase chain reaction; Tissue-specific expression 


\section{INTRODUCTION}

Dairy goat milk has a composition closest to that of human milk. The increasing consumption of dairy goat milk has stimulated intense research interest in dairy goat breeding for high lambing performance, which is important for improving production costs and efficiency. However, lambing performance in dairy goats has not been optimized owing to a lack of effective dairy goat breeding projects, so it is reasonable to investigate solutions by targeting crucial factors in animal reproduction.

Competent oocytes have a strong relationship with successful fertilization and embryo development, and granulosa cell (GC) apoptosis plays an essential role in their formulation (Han et al., 2006). In mammalian ovarian follicles, GCs constitute the vast majority of the surrounding cells of maturing oocytes. The surface of mural GCs contains exclusively folliclestimulating hormone messenger RNA (mRNA) receptors that are essential for the preantral development of follicles (Verbraak et al., 2011). Many genes that are specifically expressed in GCs have been studied in order to gain insight into the mechanisms involved in the regulation of GC function (Lauber et al., 1993; Amsterdam, 2003; Chen et al., 2009; Tsai et al., 2010). Promoters with mural GC specificity have not been reported, which makes the screening and study of specific promoters in GCs particularly important in research on genes that function in a tissue-specific manner.

Several viral promoters/enhancers have been used to drive gene transfer and expression, including cytomegalovirus (CMV), Rous sarcoma virus long terminal repeat (RSV), and simian virus 40 . CMV promoter is the most commonly used promoter in mammalian expression plasmids (Boshart et al., 1985; Foecking and Hofstetter, 1986; Hundt et al., 2009) but has been shown to be active in a broad range of cell types as has simian virus 40 (Robbins and Ghivizzani, 1998; Kimchi-Sarfaty et al., 2003; Park et al., 2004). RSV long terminal repeat, which is activated by the growth factor ligands of tyrosine kinase receptors (Cosgaya et al., 1997), is often used to enhance gene expression (Machon et al., 1998; Majhen et al., 2010). RSV is efficient in both avian and mammalian cells after transfection (Overbeek et al., 1986; Machon et al., 1996) and thought to have tissue tropism that is preferentially directed at organs rich in tendon, bone, and muscle. These widely used promoters are apparently unsuitable to research further the mechanisms involved in the regulation of GC function.

Recently, advancements have been made in the identification of certain tissue-specific promoters for gene function studies and use in gene therapy and transgenic animal creation (Tu et al., 2009). Tissue-specific promoters such as murine tyrosinase promoter are coupled to a dimer of the tyrosinase-enhancer element for targeting melanoma cells (Siders et al., 1998), to a polymorphic epithelial mucin promoter for targeting breast tissue (Patterson and Harris 1999), to a human glial fibrillary acidic protein promoter for targeting gliomas (Vandier et al., 1998), and to ovarian-specific promoters (OSPs) of retrovirus-like elements for targeting ovarian tissue (Godwin et al., 1995; Tu et al., 2009). Until now, only 2 OSPs (OSP-1 and OSP2 ) thought to be specifically expressed in ovary have been isolated from the complementary DNA (cDNA) library of rat published by Godwin et al. (1995) and Tu et al. (2009). OSP-1 has been verified to be expressed in preantral follicles, preovulatory follicles, epithelial cells, and granulosa cells (Godwin et al., 1995) and can activate gene expression in rats and women ovary cell lines (Selvakumaran et al., 2001). However, little research about these OSPs has been carried out in dairy goat ovary and GCs. To find a promoter that is specifically expressed 
in dairy goat GCs, we applied OSP-1 and constructed the reporter vector pOSP-1-enhanced green fluorescent protein (EGFP), which was validated through restriction enzyme digestion and verified for the 1st time to regulate gene expression in dairy goat GCs.

\section{MATERIAL AND METHODS}

\section{Plasmids, primers, and general reagents}

pUC57-OSP1 containing OSP-1 was synthesized by GenScript Co., Ltd. (China). pIRES2-EGFP and pCDNA3.1(+) were stored in our laboratory. The primers and endonuclease sites are listed in Table 1. X-gal and isopropyl-beta-D-thiogalactopyranoside were from Promega (USA). The RNAprep pure Blood Kit and TIANScript cDNA Kit used were from Tiangen (China).

\begin{tabular}{lll}
\multicolumn{2}{c}{ Table 1. Primers and endonuclease sites used in this study. } \\
\hline Name & Sequence $\left(5^{\prime}-3^{\prime}\right)$ & Endonuclease sites \\
\hline OSP-1F & GCTAGCAGATCTCAGAGGTACCTAAAACAAGTTG & Nhe and $B g l I I$ \\
OSP-1R & CAAGCTTAGACTGGCGCGCCTAGCAG & HindIII \\
EGFP1F & GATATCATGGTGAGCAAGGGCGAGG & EcoRV \\
EGFP1R & TCTAGACCGCTTTACTTGTACAGCTC & XbaI \\
EGFP2F & ATGGTGAGCAAGGGCGAGG & \\
EGFP2R & CCGCTTTACTTGTACAGCTC & \\
\hline
\end{tabular}

$\mathrm{F}=$ forward; $\mathrm{R}=$ reverse. Underlined sequences mean restriction enzyme cutting site protection base.

\section{Culture medium, reagents, and cells}

Dulbecco's modified Eagle's medium/Ham's F-12 (D-MEM/F12), optiMEM ${ }^{\mathrm{TM}}$ Reduced Serum Medium (GIBCO BRL), fetal bovine serum (FBS, Hyclone), Lipofectamine ${ }^{\mathrm{TM}}$ 2000, 100 $\mathrm{IU} / \mathrm{mL}$ each of penicillin and streptomycin (Invitrogen), 70- $\mu \mathrm{m}$ cell strainer (BIOLGIX, USA), six-well plates (NUNC) were used in this study for cell culture and tranfection. The human ovarian cell line HO-8910 used in this study was stored in our laboratory. Dairy goat GCs, dairy goat mammary epithelial cells, and fetal fibroblast cells were cultured by our laboratory.

\section{Isolation of dairy goat GCs}

Experiments were conducted in accordance with the Animal (Scientific Procedures) Act of China. Three-year-old Guanzhong dairy goats in estrus were selected. After the animals were slaughtered, their ovaries were transported to the laboratory at $27^{\circ}-33^{\circ} \mathrm{C}$ within $2 \mathrm{~h}$. The surrounding tissue was removed, and the ovaries were rinsed with running tap water $\left(27^{\circ}-33^{\circ} \mathrm{C}\right)$ and subsequently submersed in sterilized saline containing $100 \mathrm{IU} / \mathrm{mL}$ penicillin and $100 \mu \mathrm{g} /$ $\mathrm{mL}$ streptomycin and maintained at $30^{\circ}-35^{\circ} \mathrm{C}$ (Han et al., 2006). Dairy goat GCs were collected by aspirating follicular fluid from 3- to 6-mm healthy follicles with a disposable syringe (Verbraak et al., 2011). Collected cells were washed twice through centrifugation at $300 \mathrm{~g}$ for $5 \mathrm{~min}$ at room temperature with D-MEM/F12 culture medium containing 10\% FBS supplemented with $100 \mathrm{IU} / \mathrm{mL}$ penicillin and $100 \mu \mathrm{g} / \mathrm{mL}$ streptomycin. Cumulus oocyte complexes were removed from the cell suspension through filtration through a $70-\mu \mathrm{m}$ cell strainer and discarded. 


\section{Culture of dairy goat mural GCs}

Viable GCs were cultured for $48 \mathrm{~h}$ at $37^{\circ} \mathrm{C}$ in a $5 \% \mathrm{CO}_{2}$ atmosphere on six-well plates (Picton et al., 1999). Cells growing at 70-80\% confluence on six-well tissue culture plates were used for transient transfection assays.

\section{Construction of pOSP-1-EGFP}

Using primer pairs OSP-1 and EGFP1, we amplified promoter OSP-1 and EGFP genes from pUC57- OSP1 and pIRES2-EGFP, respectively, using polymerase chain reaction (PCR). The resultant EGFP gene was first digested with $E c o$ RV and $X b a I$ and cloned into correspondent sites of pCDNA3.1(+), yielding pCMV-EGFP. The OSP-1 promoter was then digested with $B g l \mathrm{II}$ and HindIII and cloned into correspondent sites of pCMV-EGFP, yielding pOSP-1-EGFP.

\section{Transient tranfection}

Dairy goat GCs, dairy goat mammary epithelial cells, fetal fibroblast cells, and HO8910 were implemented in this study. When cells reached $80-90 \%$ confluence, 3 dishes of each cell type were randomly used for transient transfection assays. Transient transfections were carried out using Lipofectamine ${ }^{\mathrm{TM}} 2000$, and complete medium was replaced with optiMEM ${ }^{\mathrm{TM}}$ Reduced Serum Medium $4 \mathrm{~h}$ before transfection. In all cases, the total amount of DNA transfected was brought to $4 \mu \mathrm{g} / \mathrm{well}$. Cells were incubated for $20 \mathrm{~min}$ with the DNA-lipid complexes and then allowed to culture with optiMEM ${ }^{\mathrm{TM}}$ Reduced Serum Medium for at least $4 \mathrm{~h}$. Recovery followed with D-MEM/F12 with $10 \%$ FBS. The cells were incubated at $37^{\circ} \mathrm{C}$ for another $72 \mathrm{~h}$ before examining EGFP expression using fluorescent microscopy observation.

\section{cDNA clone of EGFP mRNA}

To verify the presence of EGFP mRNA in the cells, we conducted a reverse transcriptase (RT)-PCR procedure at the end of the cell culture. Cells were lysed in $1 \mathrm{~mL}$ TRIzol-A $\mathrm{A}^{+}$Reagent, and RNA was isolated from the 4 transfected cell types according to manufacturer instructions. The RNA was quantified using a GeneQuant II spectrophotometer (Pharmacia). cDNA was produced from $5 \mu \mathrm{g}$ isolated mRNA using M-MLV Reverse Transcriptase primed with oligonucleotide-dT (18 mer) followed by RNase $\mathrm{H}$ digestion. PCR amplification was performed using a primer pair of EGFP2 for 35 cycles at $94^{\circ} \mathrm{C}$ for $1 \mathrm{~min}, 50^{\circ} \mathrm{C}$ for $1 \mathrm{~min}$, and $72^{\circ} \mathrm{C}$ for $1 \mathrm{~min}$, followed by a 10 -min extension at $72^{\circ} \mathrm{C}$. PCRs were carried out in separate reaction vessels in a volume of $100 \mu \mathrm{L}$ with $0.5 \mathrm{mM}$ primers, $1.5 \mathrm{mM} \mathrm{MgCl}_{2}, 5 \mu \mathrm{L} \mathrm{cDNA}, 200 \mu \mathrm{M}$ deoxyribonucleotide triphosphates, and $5 \mathrm{U}$ Taq DNA polymerase. Products were examined on $1.5 \%$ agarose mini-gels at $120 \mathrm{~V}$ for $30 \mathrm{~min}$ and visualized under ultraviolet light (Niles et al., 1999).

\section{RESULTS}

\section{Construction of the vector}

Restriction analysis of pOSP-1-EGFP was conducted and revealed that the vector was successfully constructed (Figure 1). 


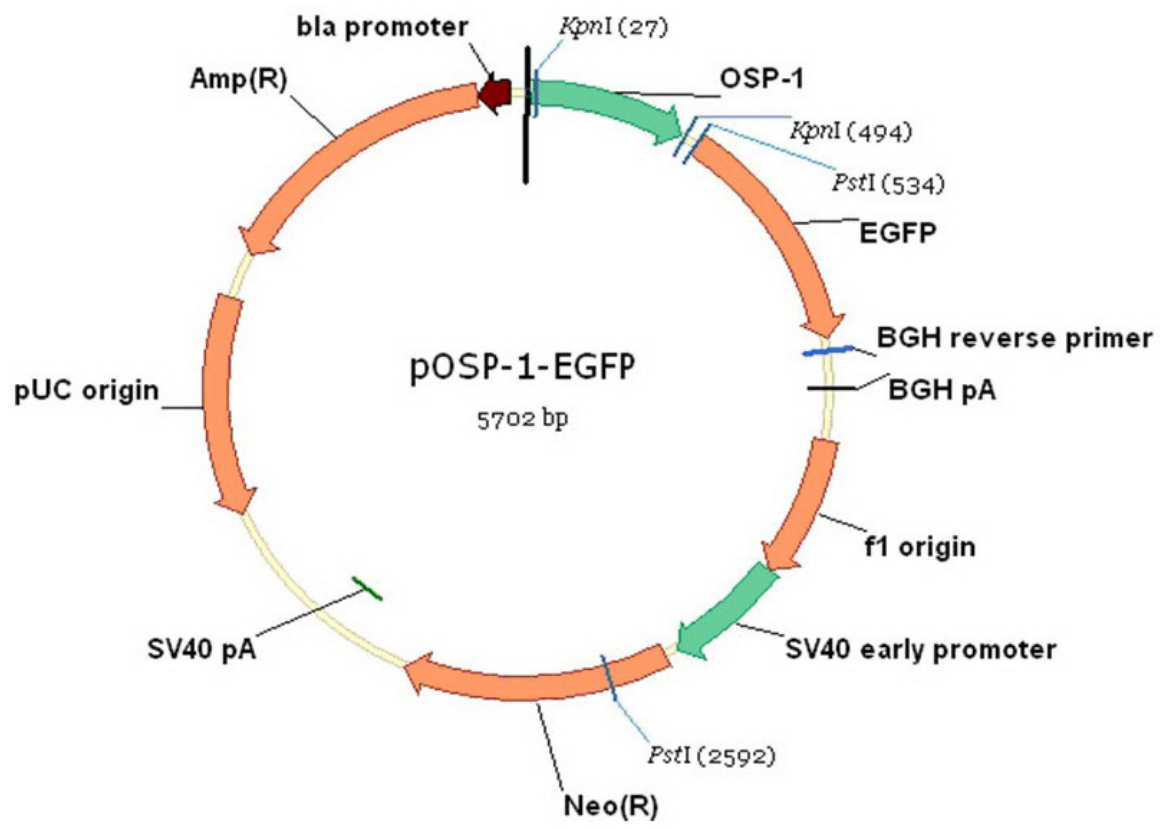

Figure 1. Structure of reporter vector pOSP-1-EGFP and identification. Taking pCDNA3.1(+) as backbone, OSP-1 promoter and enhanced green fluorescent protein (EGFP) gene of 483 and $786 \mathrm{bp}$ were amplified and cloned into this vector. EGFP driven by OSP-1 was used as reporter for tissue-specific specificity detection of OSP-1.

\section{Isolation and culture of dairy goat GCs}

Dairy goat GCs isolated from dairy goat ovaries were in suspension and displayed a spherical shape when they were inoculated into a culture flask. The cells then began to sink, contact, and anchor to the bottom and cluster over time. After of $48 \mathrm{~h}$, the cells were found in clusters or as single cells (Figure 2A), which is consistent with the results of previous research (Areekijseree et al., 2006). After 5 days of culture, the cells were nearly all round, and the bottom of the plate was covered with a single layer of GCs (Figure 2B).

\section{Detection of EGFP expression in different cells}

After transient transfection of the reporter vector pOSP-1-EGFP into cultured cells, EGFP intensity was detected under an inverted fluorescence microscope after $2 \mathrm{~h}$. Green fluorescence appeared only in GCs and HO-8910 rather than in mammary epithelial cells and fetal fibroblast cells, which demonstrated the tissue-specific expression of EGFP driven by OSP-1 (Figure 3).

\section{RT-PCR and real-time PCR analysis of EGFP mRNA}

To verify tissue-specific transcription of EGFP directed by OSP-1, we detected the 
RT-PCR products using 1.5\% agarose gel electrophoresis. The transcripts of EGFP appeared in GCs and HO-8910 (Figure 4), further confirming that OSP-1 could drive specific gene expression in dairy goat GCs.
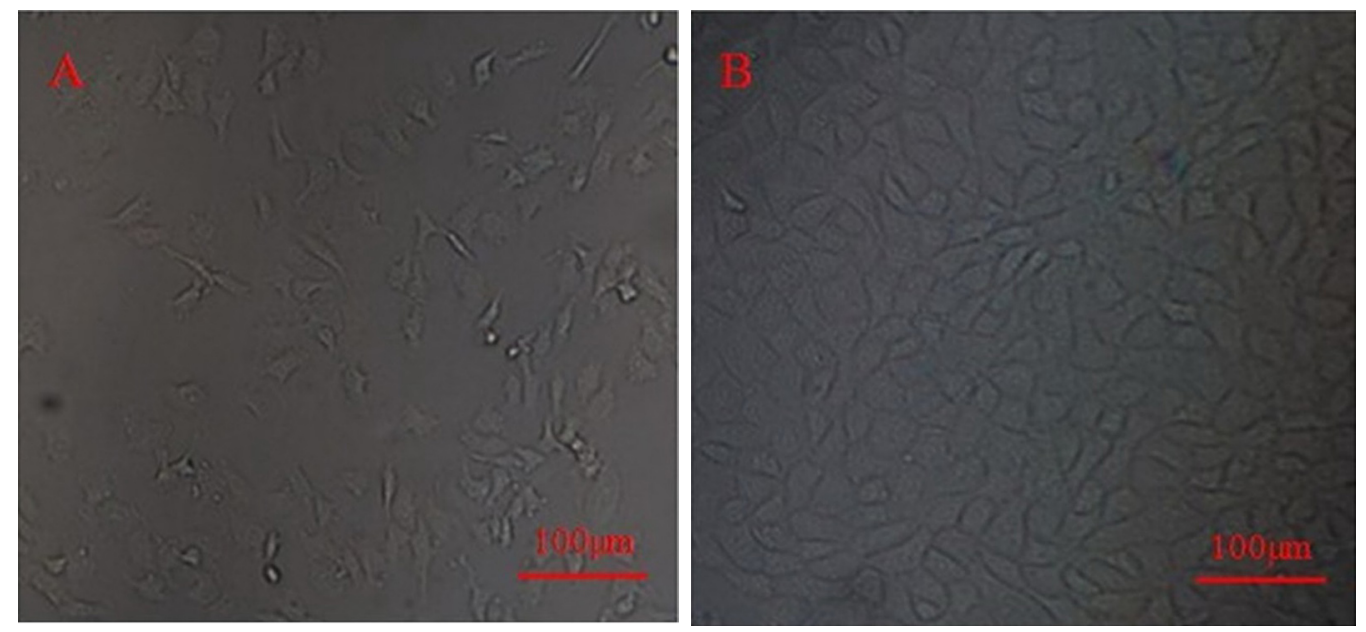

Figure 2. Morphology observation in vitro of dairy goat granulosa cells (GCs) cultured at different times. Isolated dairy goat GCs were cultured in D-MEM/F12 culture medium containing $10 \%$ fetal bovine serum supplemented with $100 \mathrm{IU} / \mathrm{mL}$ penicillin and $100 \mu \mathrm{g} / \mathrm{mL}$ streptomycin. The morphology of dairy goat GCs were shown as follows: A. Freshly isolated GCs cultured for 2 days. B. Freshly isolated GCs cultured for 5 days.
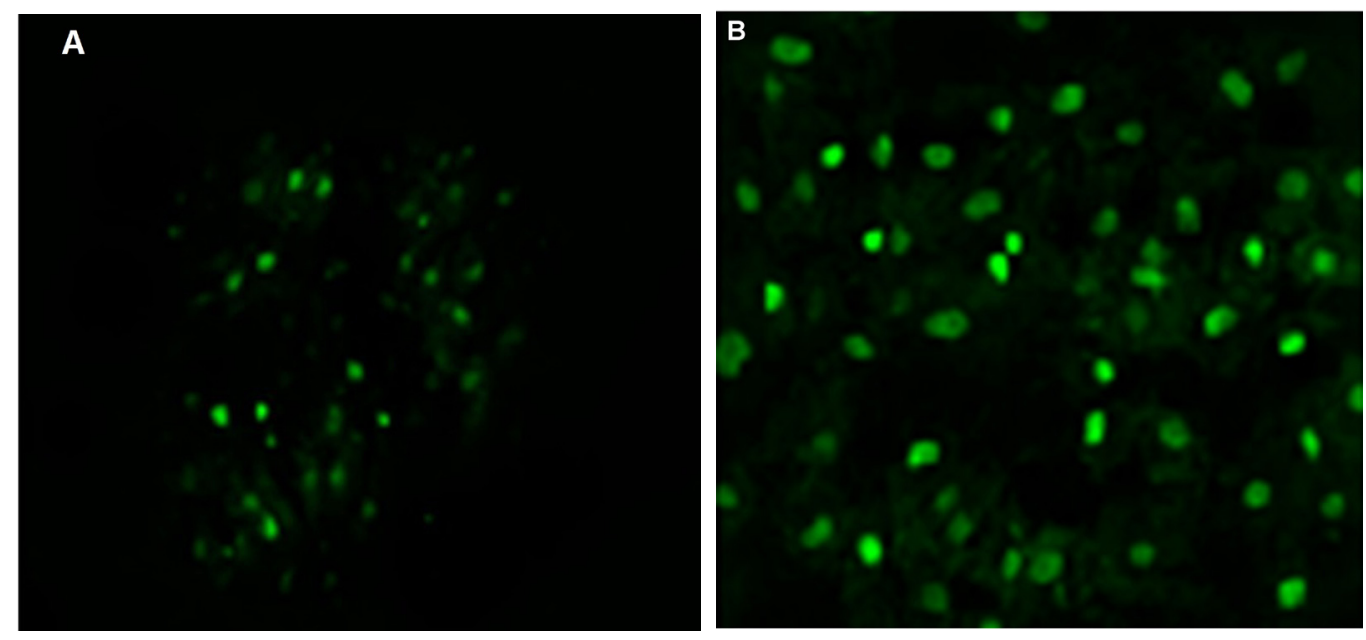

Figure 3. Green fluorescence detection in different cells after transfection (200X). After transfection of $72 \mathrm{~h}$, enhanced green fluorescent protein (EGFP) signals were detected and the results were listed as follows: A. and B. showed the EGFP signals detection in dairy goat granulosa cells (GCs), HO-891. No signals were detected in fetal fibroblast cells and mammary epithelial cells, the pictures of which are omitted. 


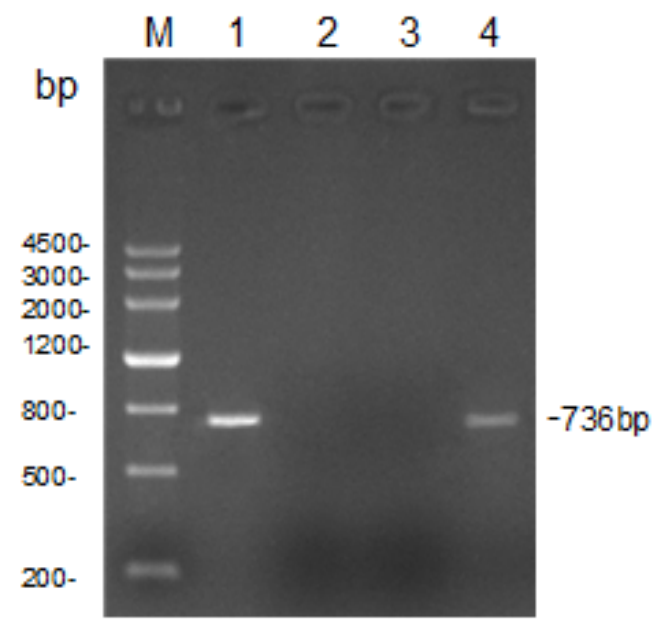

Figure 4. RT-PCR analysis of enhanced green fluorescent protein (EGFP) mRNA from different cells. Lanes 1 to 4 showed the RT-PCR production from HO-8910, mammary epithelial cells, fetal fibroblast cells, and dairy goat granulosa cells (GCs), respectively. Lane $M=$ molecular marker. A fragment of 736 bp in HO-8910 and GCs was obtained.

\section{DISCUSSION}

GCs surround oocytes and line antral follicles. They contain exclusively folliclestimulating hormone mRNA receptors that directly influence the development of mammalian ovarian follicles and strongly support oocyte maturation (Verbraak et al., 2011). These cells can also promote the penetration of spermatozoa into oocytes by inducing an acrosome reaction via their expansion of the cell mass (Romar et al., 2001) and are very useful in the determination of toxic effects of the environment, which could be cumulative and lead to abnormal embryonic development. Therefore, GCs can help considerably during the formation of competent embryos, which make them a hot topic of study in attempts to maintain successful fertilization and embryonic development.

To maximize the utility of GCs, researchers have attempted to isolate them. Mammalian GCs can be isolated and cultured in culture medium, and the GCs of cattle, large white pigs, human, chickens, and other organisms have been successfully isolated for various studies. However, few studies have undertaken the isolation of dairy goat GCs or carried out research associated with them.

In this study, we successfully isolated dairy goat GCs followed the references dealing with GC isolation in the large white pigs. To elucidate further the relationship between these functional genes and ovulation, fertility rate, and lambing, we sought a specific promoter that could drive gene expression in isolated dairy goat GCs, and we applied an OSP-1 promoter for identification.

According to the results in this study, we can conclude that rat OSP-1 can be used as a regulatory element in isolated dairy goat GCs to research the functional genes that maintain ovarian function and regulate dairy goat follicle formation and maturation. Furthermore, our results are likely to reveal the relationship between these functional genes and ovulation, fer- 
tility rate, and lambing, thus providing a feasible method for dairy goat molecular breeding and reproduction.

\section{ACKNOWLEDGMENTS}

Research supported by grants from the Twelfth Five-Year Plan of the National Science and Technology Project in Rural Areas (\#2011BAD28B05-3).

\section{REFERENCES}

Amsterdam A (2003). Novel genes regulated by gonadotropins in granulosa cells: new perspectives on their physiological functions. Mol. Cell Endocrinol. 202: 133-137.

Areekijseree M and Vejaratpimol R (2006). In vivo and in vitro study of porcine oviductal epithelial cells, cumulus oocyte complexes and granulosa cells: a scanning electron microscopy and inverted microscopy study. Micron 37: 707-716.

Boshart M, Weber F, Jahn G, Dorsch-Hasler K, et al. (1985). A very strong enhancer is located upstream of an immediate early gene of human cytomegalovirus. Cell 41: 521-530.

Chen AQ, Wang ZG, Xu ZR, Yu SD, et al. (2009). Analysis of gene expression in granulosa cells of ovine antral growing follicles using suppressive subtractive hybridization. Anim. Reprod. Sci. 115: 39-48.

Cosgaya JM, Perez-Juste G, Castillo AI and Aranda A (1997). Growth factor ligands of tyrosine kinase receptors activate the Rous sarcoma virus promoter by a Ras- and Raf-dependent mechanism. Gene 188: 291-293.

Foecking MK and Hofstetter H (1986). Powerful and versatile enhancer-promoter unit for mammalian expression vectors. Gene 45: 101-105.

Godwin AK, Miller PD, Getts LA, Jackson K, et al. (1995). Retroviral-like sequences specifically expressed in the rat ovary detect genetic differences between normal and transformed rat ovarian surface epithelial cells. Endocrinology 136: 4640-4649.

Han ZB, Lan GC, Wu YG, Han D, et al. (2006). Interactive effects of granulosa cell apoptosis, follicle size, cumulusoocyte complex morphology, and cumulus expansion on the developmental competence of goat oocytes: a study using the well-in-drop culture system. Reproduction 132: 749-758.

Hundt W, Steinbach S, O'Connell-Rodwell CE, Bednarski MD, et al. (2009). The effect of high intensity focused ultrasound on luciferase activity on two tumor cell lines in vitro, under the control of a CMV promoter. Ultrasonics 49: 312-318.

Kimchi-Sarfaty C, Arora M, Sandalon Z, Oppenheim A, et al. (2003). High cloning capacity of in vitro packaged SV40 vectors with no SV40 virus sequences. Hum. Gene Ther. 14: 167-177.

Lauber ME, Kagawa N, Waterman MR and Simpson ER (1993). cAMP-dependent and tissue-specific expression of genes encoding steroidogenic enzymes in bovine luteal and granulosa cells in primary culture. Mol. Cell Endocrinol. 93: 227-233.

Machon O, Hejnar J, Hajkova P, Geryk J, et al. (1996). The LTR, v-src, LTR provirus in H-19 hamster tumor cell line is integrated adjacent to the negative regulatory region. Gene 174: 9-17.

Machon O, Strmen V, Hejnar J, Geryk J, et al. (1998). Sp1 binding sites inserted into the Rous sarcoma virus long terminal repeat enhance LTR-driven gene expression. Gene 208: 73-82.

Majhen D, Brozovic A, Buger T, Gabrilovac J, et al. (2010). Vincristine-resistant human laryngeal carcinoma cells demonstrate increased Rous sarcoma virus promoter activity. Life Sci. 87: 468-474.

Niles LP, Wang J, Shen L, Lobb DK, et al. (1999). Melatonin receptor mRNA expression in human granulosa cells. Mol. Cell Endocrinol. 156: 107-110.

Overbeek PA, Lai SP, Van Quill KR and Westphal H (1986). Tissue-specific expression in transgenic mice of a fused gene containing RSV terminal sequences. Science 231: 1574-1577.

Park CW, Park YM, Lee GT, Lee Y, et al. (2004). Targeting of therapeutic gene expression to the liver by using liver-type pyruvate kinase proximal promoter and the SV40 viral enhancer active in multiple cell types. Biochem. Biophys. Res. Commun. 314: 131-137.

Patterson A and Harris AL (1999). Molecular chemotherapy for breast cancer. Drugs Aging 14: 75-90.

Picton HM, Campbell BK and Hunter MG (1999). Maintenance of oestradiol production and expression of cytochrome P450 aromatase enzyme mRNA in long-term serum-free cultures of pig granulosa cells. J. Reprod. Fertil. 115: 67-77.

Robbins PD and Ghivizzani SC (1998). Viral vectors for gene therapy. Pharmacol. Ther. 80: 35-47. 
Romar R, Coy P, Campos I, Gadea J, et al. (2001). Effect of co-culture of porcine sperm and oocytes with porcine oviductal epithelial cells on in vitro fertilization. Anim. Reprod. Sci. 68: 85-98.

Selvakumaran M, Bao R, Crijns AP, Connolly DC, et al. (2001). Ovarian epithelial cell lineage-specific gene expression using the promoter of a retrovirus-like element. Cancer Res. 61: 1291-1295.

Siders WM, Halloran PJ and Fenton RG (1998). Melanoma-specific cytotoxicity induced by a tyrosinase promoterenhancer/herpes simplex virus thymidine kinase adenovirus. Cancer Gene Ther. 5: 281-291.

Tsai HJ, Chiu CH, Wang CL and Chou CH (2010). A time-course study of gene responses of chicken granulosa cells to Salmonella enteritidis infection. Vet. Microbiol. 144: 325-333.

Tu CH, Liu WP, Huang LL, Mo YQ, et al. (2009). Cloning and transcriptional activity of a novel ovarian-specific promoter from rat retrovirus-like elements. Arch. Biochem. Biophys. 485: 24-29.

Vandier D, Rixe O, Brenner M, Gouyette A, et al. (1998). Selective killing of glioma cell lines using an astrocyte-specific expression of the herpes simplex virus-thymidine kinase gene. Cancer Res. 58: 4577-4580.

Verbraak EJ, van't Veld EM, Groot KM, Roelen BA, et al. (2011). Identification of genes targeted by FSH and oocytes in porcine granulosa cells. Theriogenology $75: 362-376$. 